\title{
Evaluation of the effect of temperature and time on the conversion factor of acrylic resin denture base material
}

\author{
Amer A. Taqa ${ }^{1, *}$, Nadira A.Hatim ${ }^{2}$, Saja Amjad A. Razzak ${ }^{3}$ \\ ${ }^{1,2}$ Professor, ${ }^{3}$ Assistant Lecturer, ${ }^{1}$ Dept. of Dental Basic Science, ${ }^{2,3}$ Dept. of Prosthetic Dentistry, College of Dentistry, University \\ of Mosul, Iraq
}

*Corresponding Author:

Email: amertaqa@hotmail.com

\begin{abstract}
Aim: To evaluate the effect of change in time, temperature (increase or decrease) on the degree of conversion and residual monomer release of the vertex heat cured acrylic resin.

Material and Methods: The total number of samples (176) were divided into three main groups cured according to ADA and three curing cycles with modifications in time and temperature, degree of conversion and residual monomer properties were measured for all the samples.

Results: Analyzed statistically by (Descriptive statistics, ANOVA and Duncan's multiple range test) and showed that both changes in time and temperature showed significant changes in the degree of conversion, residual monomer.

Conclusion: The rapid simplified and regular manufacturer's instruction curing cycles showed the best results regarding the degree of conversion, residual monomer.
\end{abstract}

Keywords: Temperature, Time, Conversion factor, Acrylic resin.

\section{Introduction}

The number of denture wearers is increasing as the number of elderly people continually growing, and poly methyl methacrylate (PMMA) is still the most frequently used material in denture base fabrication. ${ }^{1}$

The biological characteristics of denture - base resins are influenced by the monomer to polymer conversion. Despite the various methods used to initiate the polymerization of acrylic resins, the conversion of monomers to polymers is incomplete leaving residual monomer in the denture base that can leach into the saliva. $^{2,3}$

Barron et al. ${ }^{4}$ stated that the degree of conversion of resin materials is a measure of the carbon double bonds $(\mathrm{C}=\mathrm{C})$ converted into carbon single bond $(\mathrm{C}-\mathrm{C})$. There is an inverse relationship between the degree of conversion and the residual monomer content, thus the higher the former, the lower the later. ${ }^{5,6}$ The amount of residual monomer is one of the principal factors affecting the properties of acrylic resin denture bases. ${ }^{4,7-}$ 10

The purposes of this study were to evaluate the effect of change in time, temperature (increase or decrease) on the degree of conversion and residual monomer release of the vertex heat cured acrylic resin.

\section{Material and Methods}

The total number of samples (176) were prepared from vertex heat curing denture base resin material according to manufacturer's instructions powder/liquid mixing ratio (2/1). Samples were divided into three main groups as shown in Fig. 1, 2 and 3).

The Changes or modifications in temperature were controlled by the thermo state of the water bath, while changes in times were monitored by the clock timer, curing at $105^{\circ} \mathrm{C}$ was obtained by addition of salt to the water bath at a ratio of $20 \mathrm{~g}$ salt: $100 \mathrm{ml}$ water. ${ }^{11}$

Degree of Conversion Measurement Test: Three samples of vertex heat - polymerizing resin with dimensions of $10 \times 4 \times 4( \pm 0.03) \mathrm{mm}$ were prepared and stored in distilled water at $37 \pm 1{ }^{\circ} \mathrm{C}$ for 48 hour. ${ }^{12}$ After 48 hour, the samples were removed from water and dried in air and then scraped using a sharp, clean and sterile wax knife, then $1-2 \mathrm{mg}$ of the sample powder was grinded finely, under anhydrous conditions, in an agate mortar. This powder is then thoroughly mixed with $100-200 \mathrm{mg}$ of oven - dried, spectral - grade, $100-200$ mesh potassium bromide powder. The mixture is then pressed into a transparent pellet by using a mini - press. The $\mathrm{KBr}$ pellet is then mounted on a holder and placed in the sample beam of the infrared spectrophotometer. ${ }^{13}$

In the IR charts, two absorbance peaks were determined (the absorbance peak of the $\mathrm{C}=\mathrm{C}$ from the methacrylate group, and the absorbance peak of the $\mathrm{C}=\mathrm{O}$ from the ester group). An appropriate base line was drawn, the intensity of absorption was determined by calculating the areas of the peaks by the Auto CAD program. ${ }^{14}$ The degree of conversion was calculated from the following formula: ${ }^{12}$

$$
\begin{aligned}
& \mathrm{DC} \%=[1-[\mathrm{Abs}(\mathrm{C}=\mathrm{C}) / \mathrm{Abs}(\mathrm{C}=\mathrm{O})] \text { polymerized } \\
& {[\operatorname{Abs}(\mathrm{C}=\mathrm{C}) / \mathrm{Abs}(\mathrm{C}=\mathrm{O})] \text { monomer }}
\end{aligned}
$$

Residual Monomer Measurement Test: Five Samples with linear dimensions $20 \times 20 \times 3( \pm 0.03) \mathrm{mm},{ }^{15}$ 
were prepared for each cycle. After curing, each sample was introduced in sealed glass flask containing $10 \mathrm{ml}$ of distilled water at $37^{\circ} \mathrm{C}$. At appropriate times $\left(1^{\text {st }}\right.$, $2^{\text {nd }}, 3^{\text {rd }}, 4^{\text {th }}, 5^{\text {th }}, 6^{\text {th }}$ and $7^{\text {th }}$ days), the supernatants were removed and replaced by $10 \mathrm{ml}$ of fresh distilled water. The time - dependence of the monomer concentration was followed by monitoring the amount of monomer present in the supernatant medium using a CECIL 2000 UV-Visible Spectrophotometer $(\mathrm{W}=254 \mathrm{~nm})$. A linear calibration curve of methyl methacrylate (MMA) concentration as a function of the absorbance at 254 $\mathrm{nm}$ was obtained using MMA standard aqueous solutions in the range $0.025-0.5 \mathrm{mg} / \mathrm{ml}$ (Figure 4). The results were expressed as a percent of released residual monomer mass with respect to the weight of the specimen. ${ }^{15}$ Statistical analysis used in this study were Descriptive statistics, ANOVA and Duncan's multiple range test.

\section{Results}

1. The Degree of Conversion Test: IR charts (Fig. 5, 6), two absorbance peaks appeared (the absorbance peak of the $\mathrm{C}=\mathrm{C}$ from the methacrylate group at $1640 \mathrm{~cm}^{-1}$ and the absorbance peak of the $\mathrm{C}=\mathrm{O}$ from the ester group at $1720 \mathrm{~cm}^{-1}$ ). By using Auto $\mathrm{CAD}$ program, the results were calculated by one-way analysis of variance (ANOVA) for the degree of conversion test (Table 1) showed that there were significant differences $(p<0.05)$ between the three standard curing cycles and their modification groups in comparison with the standard short cycle. Mean, standard deviation and Duncan's multiple range test for the standard short cycle S1 (ADA) and its modification groups (Fig. 7) indicated that all the modification groups showed significant increase in the degree of conversion from the standard short cycle S1 (ADA), except groups S2 and S4 which showed significant decrease in the conversion from the standard cycle (ADA). Both of these groups represent decrease in the curing temperature. While groups S6 and S8 which represented decrease in the curing time showed no significant difference from the standard cycle. Duncan's multiple range test of the degree of conversion test of the standard short curing cycle (S1) with the rapid simplified and regular manufacturer's instructions curing cycle and their modifications (MRa) and (MRe) groups indicated that the standard short curing cycle (ADA) showed significant decrease in degree of conversion from the standard rapid simplified and regular heat curing cycles and all their modifications, as shown in Fig. 8 and 9. In comparison of the three standard curing cycles, it is shown that the rapid simplified had the highest conversion followed by the regular, then the standard short cycle (Fig. 10).
2. Residual Monomer Release Test: The amount of released monomer versus release period of time (in days) for the short cycle, rapid simplified and regular heat curing cycles and their modifications was illustrated in Fig. 11-13.

\section{Discussion}

1. The Degree of Conversion Test: It is shown from the results (Fig. 7) that group (S3) showed significant increase in the degree of conversion from the control S1, groups MRa3,MRe3 showed not significant decrease in degree of conversion from their standard MRa1, MRe1 cycles (Fig. 8-10) and significant increase in the degree of conversion in comparison with the standard ADA These cycles represented curing with increase of the first temperature of the curing cycle. This increase in conversion with temperature increase was stated by Beech, Bartoloni et al., and Lovell et al. ${ }^{2,16,17}$ The reasons for increased conversion are based on many factors, increased temperature decreases system viscosity, the collision frequency of unreacted active groups and radicals increases with elevated curing temperature when below the glass transition temperature. Furthermore, as temperature is raised, additional free volume increases, giving trapped radicals increased mobility, resulting in further conversion. ${ }^{18}$ Groups (S4, MRa4 and MRe2) showed significant decrease in the degree of conversion in comparison with their control groups S1, MRa1, MRe1. These groups were cured by lowering the boiling point, this indicates that reaching boiling point is necessary for increased conversion and this agrees with Harrison and Hugget, ${ }^{19}$ as they stated that it has been recommended that the polymerization cycle should include a terminal boiling treatment for at least one hour to achieve maximum monomer conversion. This finding also agrees with many authors. ${ }^{12,20,21}$ Groups (S5\&MRe3) showed increase in the degree of conversion with increasing the boiling point to $\left(105^{\circ} \mathrm{C}\right)$. This may be explained that, as the amount of monomer is reduced as a result of the polymerization, it becomes more difficult to bring the monomer and the free radical together, because the available heat stabilizes. The more the temperature rises, the faster the molecules move and the more complete is the polymerization reaction. ${ }^{17}$ Groups (S7 and MRe5) showed increase in conversion with increasing the curing time from their control groups. Authors ${ }^{15}$ showed that it is possible to optimize the conversion degree by varying the time of curing at constant temperature, while Beech ${ }^{16}$ stated that long reaction times increase the polymer yield. Groups S9 and MRe5 showed increase in conversion respectively in comparison with the control. These groups cured at prolonged boiling cycle. ${ }^{6,19}$ 
2. Residual Monomer Release Test: The highest amount of residual monomer released was observed in group $\mathrm{S} 4$ which is cured by modification of the curing temperature by lowering the boiling point, while group S5 showed lowered residual monomer than $\mathrm{S} 1$ (cured by increasing the boiling temperature). Group S7 also showed low residual monomer release (Fig. 11-13). This group cured by modification in the curing time (increase), all these results come in agreement with Mohamed et al. ${ }^{22}$ As they showed that increased temperature and extended polymerization time were accompanied by a decrease in the residual monomer content. Groups S9 and MRa8 showed low residual monomer release, these groups cured by increasing the boiling time, this comes in agreement with Dogan et al..$^{23}$ They showed that longer curing times at $100^{\circ} \mathrm{C}$ decreased the level of residual monomer. All groups showed greatest loss in the first 24 hours, this agree with many authors. ${ }^{24-25}$ After 48 hour, the content of monomer release were very low, then gradual decrease in the remaining monomer release until reach zero. Different mechanisms might help explain this reduction; it has been observed that the concentration of the residual monomer in the polymerized resin can be diminished by diffusion into water and by continuous polymerization promoted by the active radicals found in the polymer chains. ${ }^{5,2}$

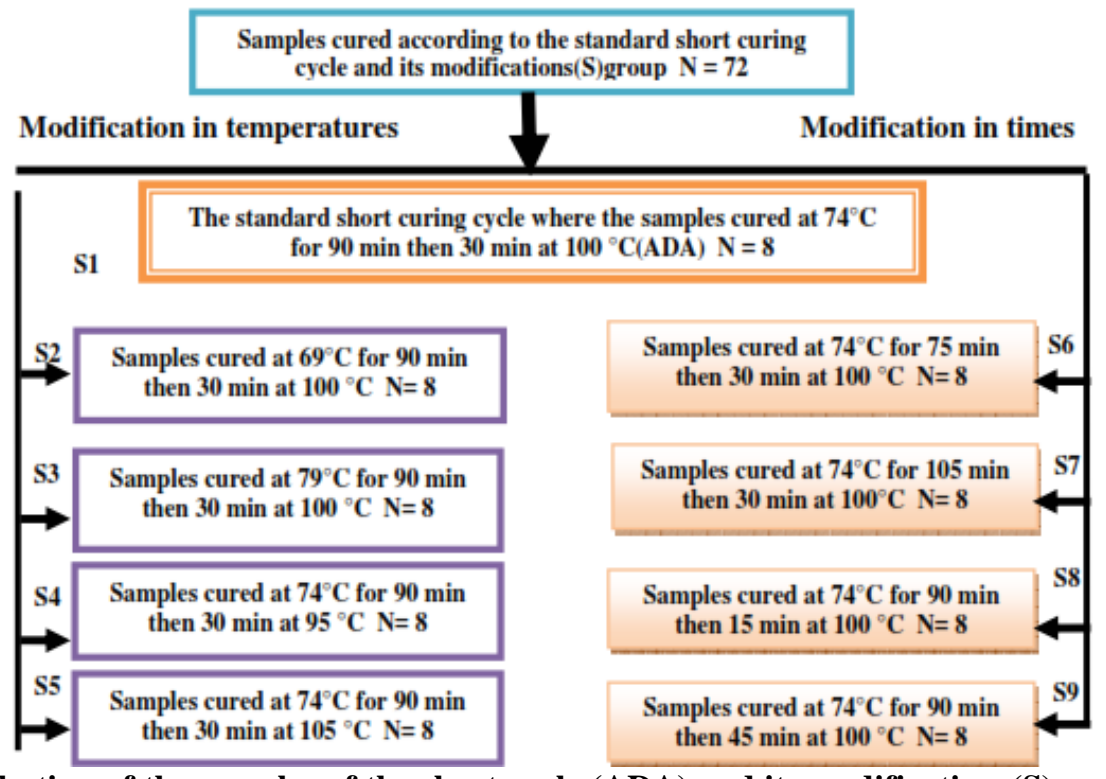

Fig. 1: The distribution of the samples of the short cycle (ADA) and its modifications(S) group

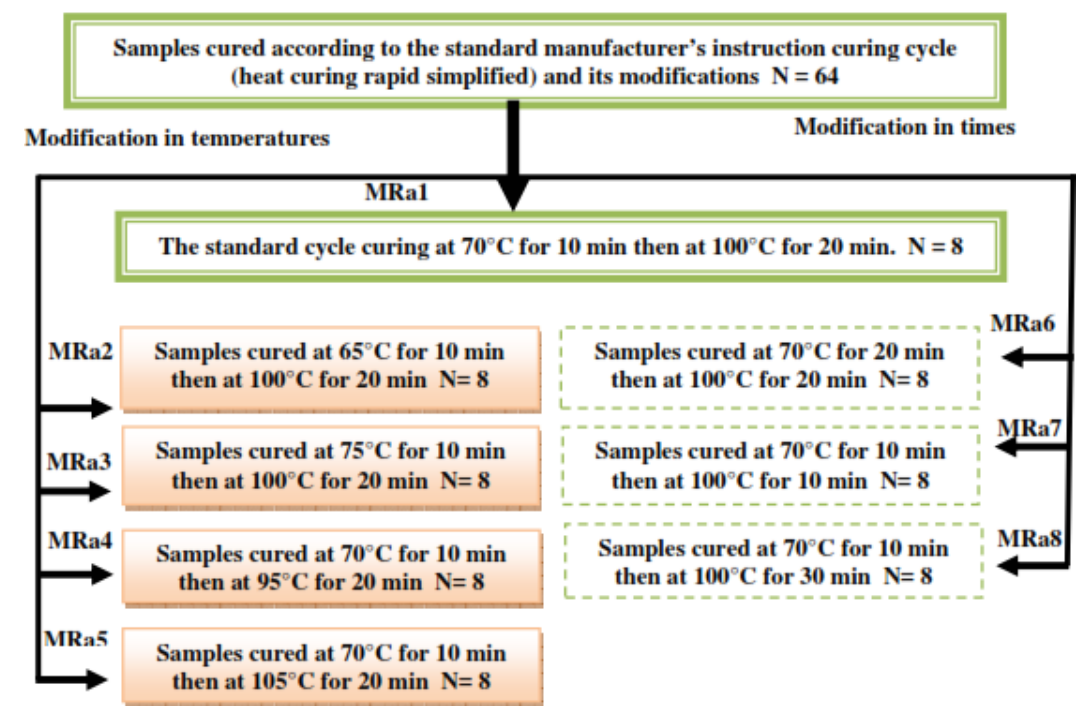

Fig. 2: The distribution of the samples of the rapid simplified manufacturer's instructions curing cycle and its modifications, (MRa) group 


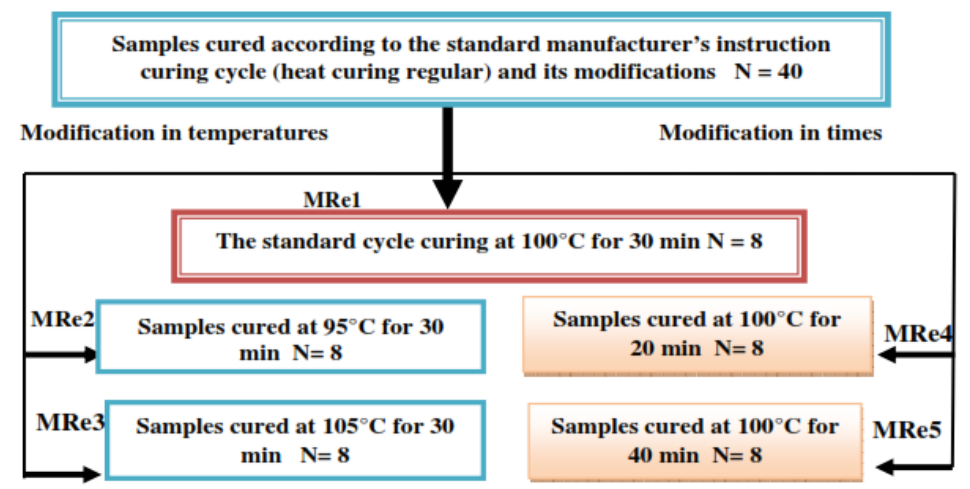

Fig. 3: The distribution of the samples of the regular manufacturer's instructions curing cycle and its modifications, (MRe) group

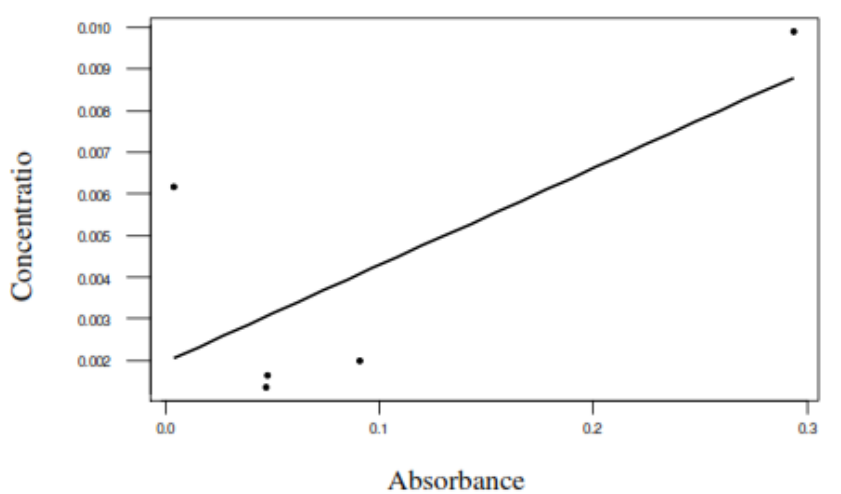

Fig. 4: Calibration curve of monomer

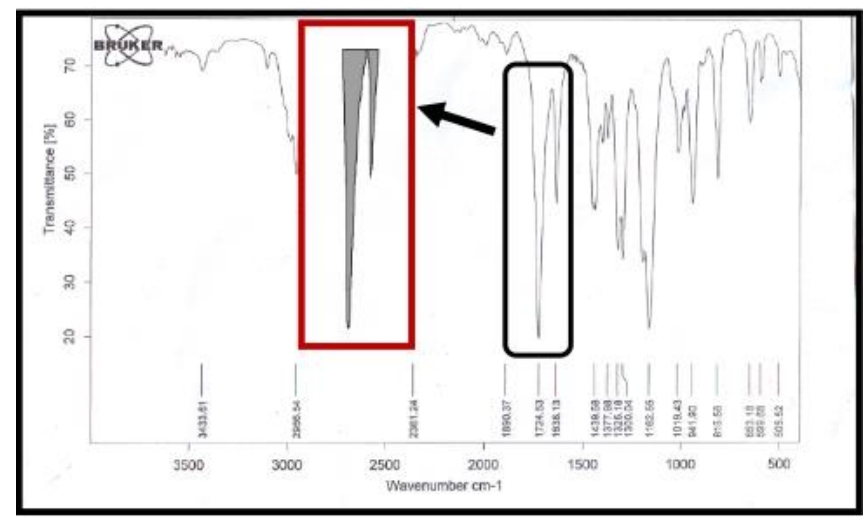

Fig. 5: Infrared spectrometer chart of the monomer (methylmethacrylate)

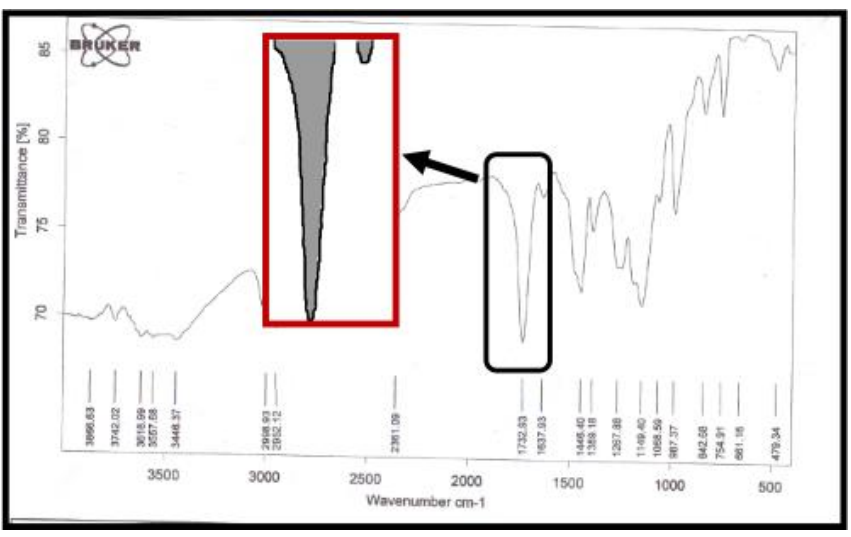

Fig. 6: Infrared spectrometer chart of the sample prepared according to the standard short cycle (ADA) 


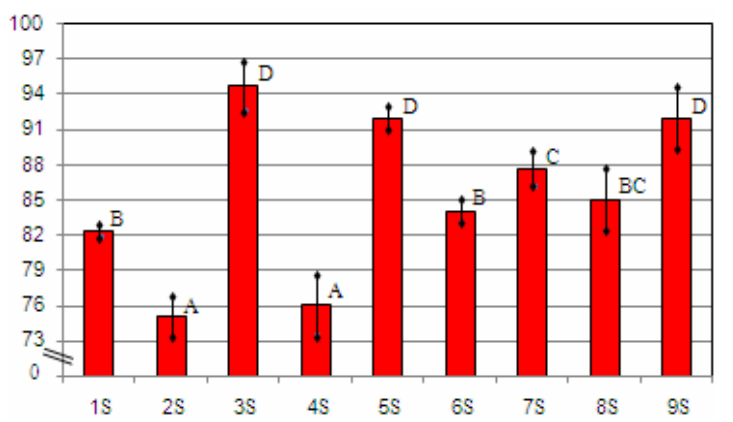

* Different letters mean significant difference at $\mathrm{p} \leq 0.05$ Fig. 7: Mean \pm SD and Duncan's Multiple Range Test of the degree of conversion test for the short cycle and its modification groups (S) group

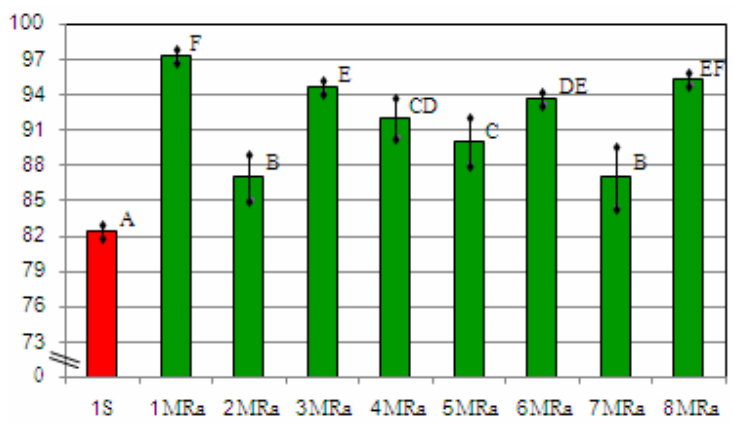

$*$ Different letters mean significant difference at $\mathrm{p} \leq 0.05$ Fig. 8: Mean \pm SD and Duncan's Multiple Range Test of the degree of conversion test for the rapid simplified heat curing cycle and its modifications in comparison with the standard short cycle

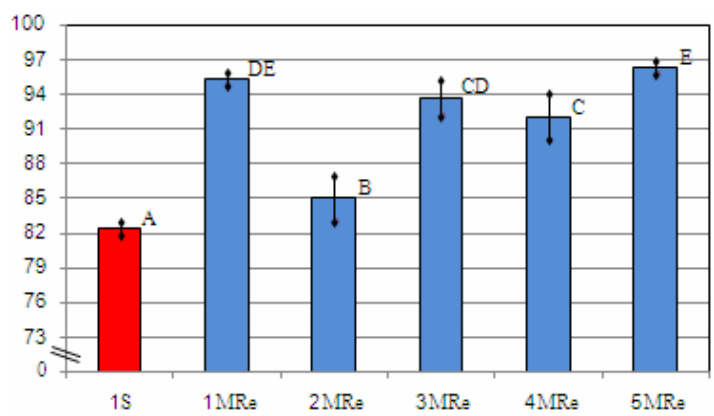

* Different letters mean significant difference at $\mathrm{p} \leq 0.05$ Fig. 9: Mean \pm SD and Duncan's Multiple Range Test of the degree of conversion test for the regular heat curing cycle and its modifications (MRe) group and the standard short cycle

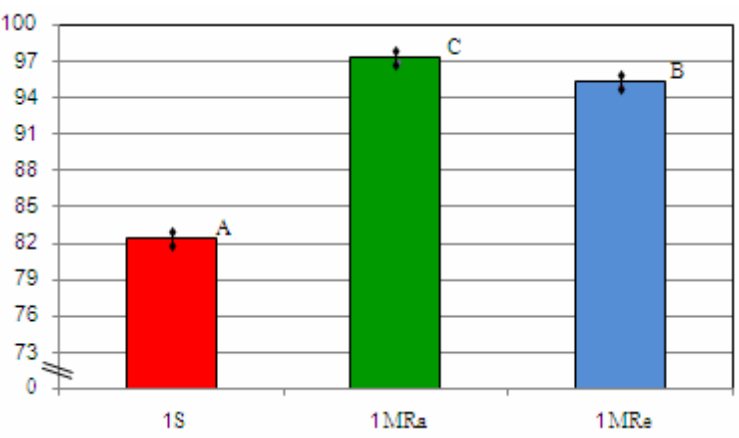

* Different letters mean significant difference at $p \leq 0.05$ Fig. 10: Mean \pm SD and Duncan's Multiple Range Test of the degree of conversion test for the three standard curing cycles (short curing cycle, rapid simplified and regular heat curing cycles)

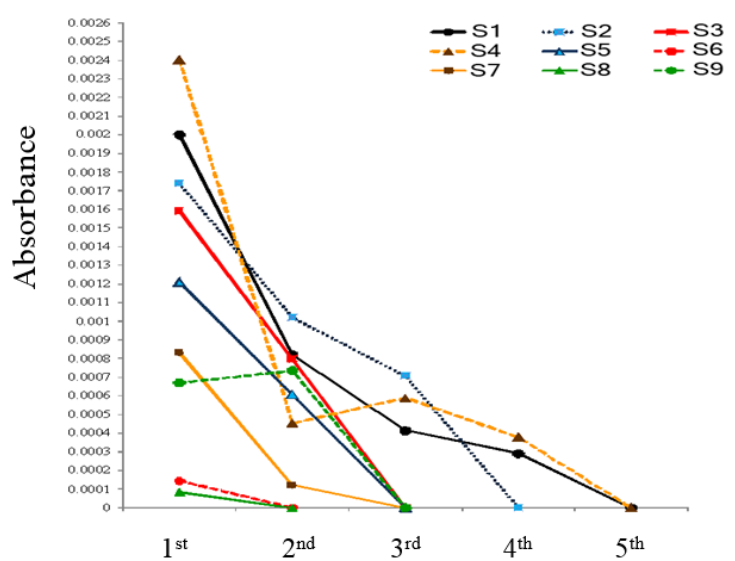

Fig. 11: The residual monomer release of the short cycle and its modification groups

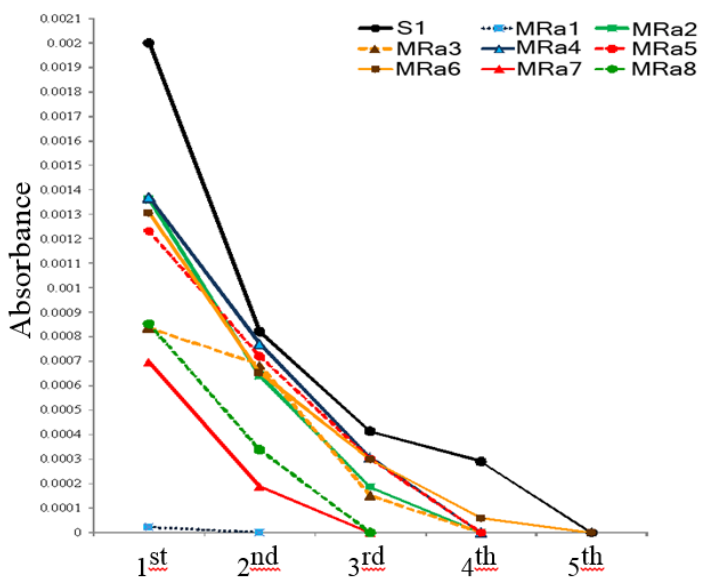

Fig. 12: The residual monomer release of the rapid simplified curing cycle and its modification groups in comparison with the standard short cycle (ADA) 


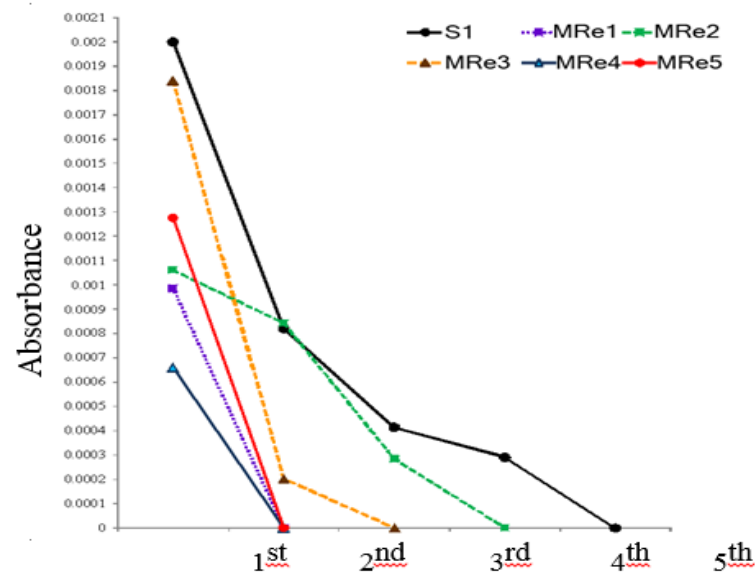

Fig. 13: The residual monomer release of the regular heat curing cycle and its modification groups in comparison with the standard short cycle (ADA)

Table 1: The one way analysis of variance (ANOVA) of the degree of conversion test For the short curing cycle, rapid simplified and regular heat curing cycles and their modification groups(without additives)

\begin{tabular}{|c|c|c|c|c|c|c|}
\hline Groups & & $\begin{array}{c}\text { Sum of } \\
\text { squares }\end{array}$ & df & $\begin{array}{c}\text { Mean } \\
\text { square }\end{array}$ & $\mathbf{F}$ & Sig. \\
\hline \multirow[t]{3}{*}{$\mathrm{S} 1 \longrightarrow \mathrm{S} 9$} & Between groups & 1158.519 & 8 & 144.815 & \multirow{3}{*}{39.495} & \multirow{3}{*}{$0.000 *$} \\
\hline & Within groups & 66.00 & 18 & 3.667 & & \\
\hline & Total & 1224.519 & 26 & & & \\
\hline \multirow{3}{*}{$\begin{array}{c}\text { S1 with } \\
\text { MRa1 } \longrightarrow \text { MRa8 }\end{array}$} & Between groups & 565.630 & 8 & 70.704 & \multirow{3}{*}{32.356} & \multirow{3}{*}{$0.000^{*}$} \\
\hline & Within groups & 39.333 & 18 & 2.185 & & \\
\hline & Total & 604.963 & 26 & & & \\
\hline \multirow{3}{*}{$\begin{array}{c}\text { S1 with } \\
\text { MRe1 } \longrightarrow \text { MRe5 }\end{array}$} & Between groups & 498.444 & 5 & 99.689 & \multirow{3}{*}{52.776} & \multirow{3}{*}{$0.000 *$} \\
\hline & Within groups & 22.667 & 12 & 1.889 & & \\
\hline & Total & 521.111 & 17 & & & \\
\hline
\end{tabular}

*Significant difference at $\mathrm{p}<0.05$. df: Degree of freedom

\section{Conclusion}

1. Curing the resin by following the manufacturer's instructions curing cycle of the supplied resin (At $70{ }^{\circ} \mathrm{C}$ for 10 minutes then at $100^{\circ} \mathrm{C}$ for 20 minutes or at $100^{\circ} \mathrm{C}$ for 30 minutes) provided the optimal properties regarding the highest conversion and lowest amount of released residual monomer.

2. Modifications in the curing temperature showed more significant effect on the studied properties than modifications in time.

3. In general, raised temperature and extended polymerization time showed improved conversion, and lowering the monomer release.

4. Increasing the time at boiling during curing for the three studied curing cycles resulted in improvement in the degree of conversion.

Funding: No funding sources.

Conflict of interest: None declared.

\section{References}

1. Brown LR, Flavin C, French H: A new economy for a new century. State of the world. 1999; Cited in Ožen J, Sipahi C, Caglar A, Dalkiz M: In vitro cytotoxicity of glass and carbon Fiber - reinforced heatpolymerized acrylic resin denture base material. Turk $J$ Med Sci 2005;63:121-26.

2. Bartoloni JA, Murchison DF, Wofford DT, Sarkar NK. Degree of conversion in denture base materials for varied polymerization techniques. J Oral Rehabil 2000;27:488-493.

3. Ebadian B, Razari M, Soleimanpour S, Mosharraf R. Evaluation of tissue reaction to some denture - base materials: an animal study. J Contemp Dent Prac 2008;9:1-9.

4. Barron DJ, Rueggeberg FA, Schuster GS. A comparison of monomer conversion and inorganic filler content in visible light - cured denture resins. Dent Mater 1992;8:274-77.

5. Vallittu PK, Miettinen V, Alakuijala P. Residual monomer content and its release into water from denture base materials. Dent Mater 1995;11:338-42.

6. Vallittu PK, Ruyter IE, Buykuilmaz S. Effect of polymerization temperature and time on the residual monomer content of denture base polymers. Eur J Oral Sci 1998;106:588-93.

7. Amer A. Taqa, A.-H. A. Suliman, Aimer J. S. Al-Taee, Evaluation of the Degree of Conversion and Curing Depth for the Composite Resin. Adv Biomed Sci 2016;1(1):1-9.

8. Al - Doori D, Huggett R, Bates JF, Brooks SCA. Comparison of denture base acrylic resins polymerized 
by microwave irradiation and by conventional water bath curing systems. Dent Mater 1988;4:25-32.

9. Amer A. Taqa, Ahmed Asem and Omer A. Mohsen. The effect of different curing techniques on the degree of bond conversion for different types of acrylic resin materials. $A l$ - Rafidain Dent J 2013;13(2).

10. Yimaz H, Aydn C, Aglar A, Yasar A. The effect of glass fiber reinforcement on the residual monomer content of two denture base resins. Quintessence Int 2003;34:148-153.

11. Svehla G. Vogel's textbook of macro and semimicroqualitative inorganic analysis. $5^{\text {th }}$ Edition. London and New York Longman group.1979 LTD. P.9.

12. Urban VM, Machado AL, Vergani CE, Jorge EG, Santos LP, Leite ER, Canevarolo SV. Degree of conversion and molecular weight of one denture base and three reline submitted to post - polymerization treatments. Mater Res 2007;10:1-13.

13. Parikh VM: Absorption spectroscopy of organic molecules. Addison - Wasly Co. 1974;1-43.

14. Nomoto R, Asada M, Mccabe JF, Hirano S. Light exposure required for optimum conversion of light activated resin systems. Dent Mater 2006;22:1135-42.

15. Azzarri MJ, Cortizoa MS, Alessandrini JL. Effect of the curing conditions on the properties of an acrylic denture base resin microwave - polymerized. J Dent 2003;31:463-68.

16. Beech DR: Molecular weight distribution of denture base acrylic. J Dent 1975;3:19-24.

17. Lovell LG, Lu H, Elliott JE, Stansbury JW, Bowman $\mathrm{CN}$. The effect of cure rate on the mechanical properties of dental resins. Dent Mater 2001;17:504-11.

18. Daronch M, Rueggberg FA, De Goes MF. Monomer conversion of pre-heated composites. J Dent Res 2005;7:663-67.
19. Harrison A, Huggett R. Effect of the curing cycle on residual monomer levels of acrylic resin denture base polymers. J Dent 1992;20:370-74.

20. Urban VM, Cass QB, Oliverira RV, Giampaolo ET, Machado AL. Development and application of methods for determination of residual monomer in dental acrylic resins using high performance liquid chromatography. Biomed Chromatogr 2006;20: 369-76.

21. Jorge JH, Giampaolo ET, Machado AL, Pavarina AC, Carlos IZ. Biocompatibility of denture base acrylic resins evaluated in culture of L929 cells. Effect of polymerization cycle and post - polymerization treatments. Gerodontol 2007; 24:52-7.

22. Mohamed SH, Al-Jadi AM, Ajaal T. Using of hPlC analysis for evaluation of residual monomer content in denture base material and their effect on mechanical properties. J Phys Sci 2008;2:127-35.

23. Dogan A, Bek NN, Usanmaz. The effect of prepaeration conditions of acrylic denture base materials on the level of residual monomer, mechanical properties and water absorption. J Dent 1995;23:313-18.

24. Szabo G, Stafford GD, Huggett R, Brooks SC. The loss of residual monomer from denture base polymers coated with an ultraviolet light - activated polymer. Dent Mater 1987;3:64-66.

25. De-Oliverira VM, Leon BL, Del Bel Cury AA, Consani S. Influence of number and position of flasks in the monomer release, knoop hardness and porosity of a microwave - cured acrylic resin. J Oral Rehabil 2003;30:1104-08.

How to cite the article: Taqa A., Hatim N., Amjad S., Razzak A. Evaluation of the effect of temperature and time on the conversion factor of acrylic resin denture base material. Int Dent J Student's Res 2018;6(3):44-50. 